\title{
Moving a Taxi Sector to Become Electric: Characterizing Taxi Drivers Interested in Purchasing a Full Electric Vehicle
}

\author{
Milan Tamis * and Robert van den Hoed \\ Department of Urban Technology, Faculty of Technology, Amsterdam University of Applied Sciences, \\ 1097 DZ Amsterdam, The Netherlands; r.van.den.hoed@hva.nl \\ * Correspondence: m.r.tamis@hva.nl
}

Received: 4 December 2019; Accepted: 2 March 2020; Published: 4 March 2020

check for updates

\begin{abstract}
Electrification of mobility exceeds personal transport to increasingly focus on particular segments such as city logistics and taxis. These commercial mobility segments have different motives to purchase a full electric vehicle and require a particular approach to incentivize and facilitate the transition towards electric mobility. A case where a municipality was successful in stimulating the transition to electric mobility is the taxi sector in the city of Amsterdam. Using results from a survey study $(n=300)$, this paper analyses the differences in characteristics between taxi drivers that either have or do not have interest in purchasing a full electric taxi vehicle. Results show a low intention across the sample to adopt a full electric vehicle and no statistically significant differences in demographics between the two groups. Differences were found between the level of acceptability of the covenant, the rated attractiveness of the incentives, the ratings of full electric vehicle attributes and the consultation of objective and social information sources. These results can be used by policy makers to develop new incentives that target specific topics currently influencing the interest in a full electric taxi vehicle.
\end{abstract}

Keywords: case study; commercial fleet; full electric vehicles; incentives; research; taxi; user behaviour

\section{Introduction}

Electric mobility is increasing at a fast pace, leading to increasing penetration rates of electric vehicles (EV) and the development of accompanying charging infrastructure. One of the leading countries in this respect is the Netherlands, where the market share of electric vehicles has grown to $5-10 \%$ in 2019 and where extensive infrastructure was built to support the need for public charging [1]. With EV adoption increasing among Dutch households, specific commercial mobility sectors are also targeted to contribute to this transition, with the taxi sector as a prime example. Taxis are compelling in this case, as they operate in inner city districts and contribute to local air quality problems. The municipality of Amsterdam signed a covenant (voluntary agreement) with most Amsterdam based official taxi organizations at the end of 2015 with the aim of creating a full electric taxi fleet before 2025 [2]. Through this covenant, the official taxi organizations declared their commitment towards the transition to full electric passenger transport. The municipality facilitates this transition by several policy measures, including (i) purchase subsidies, (ii) placement of (fast) chargers, (iii) a priority incentive at particular taxi stands and (iv) an environmental zone. The policy measures thus include incentives to stimulate the transition and persuade taxi drivers to purchase full electric vehicles (FEVs), but also include facilitation of FEV adopters through charging infrastructure and restrictions for non-adopters with designated environmental zones. The goal of this incentive program is to encourage taxi drivers to switch to FEVs in the upcoming years. The main difference with EV adoption amongst 
consumers is that, for taxi drivers, the vehicle itself is a prerequisite for all work-related activities while the switch to FEVs will be both stimulated by incentives as well as enforced through regulation.

Insight into the adoption dynamics of taxi drivers is important for policy makers in order to optimize supporting and regulation schemes. In most cases, Dutch taxi fleets are not managed by the overarching taxi organization, who usually function as an administrative unit. Rather, vehicles are bought, operated and maintained by the individual taxi drivers themselves. The Amsterdam based taxi service is thus made up of thousands of individual entrepreneurs, all of whom are expected to switch to EVs in the upcoming years (the only exception is the Amsterdam based Taxi Electric, who operates a full electric taxi fleet and hires employees rather than entrepreneurs to operate vehicles. As the name indicates, Taxi Electric already operates an entire full electric taxi fleet. Since we focus on entrepreneurs and their individual decisions to purchase FEVs, data from Taxi Electric employees are not included in this paper). In this paper, we will discuss the results of a survey conducted in September 2017, centered around the perceptions of Amsterdam-based taxi drivers regarding (1) the covenant between the municipality of Amsterdam and the Amsterdam based taxi organizations, (2) the incentives and measures used by the municipality in line with the covenant, (3) the evaluations of FEV attributes, (4) the consultation of objective and social information sources and (5) the general interest in purchasing an FEV.

This paper is structured as followed: first, a theoretical framework is described to outline the concepts used in the research. Second, sample, procedure, measure and analysis are described in the methodology section. Third, results are presented, focusing on the differences in characteristics between taxi drivers that are currently driving an internal combustion engine vehicle (ICEV). Last, the paper draws conclusions on how differences in perspectives can be characterized and how this may impact policies to stimulate the uptake of electric mobility for taxis and possible also for other commercial sectors.

\section{State of the Art}

In order to gain insight into how commercial sectors such as the taxi sector may shift towards electric mobility, we draw on consumer research regarding adoption of sustainable technologies. To our knowledge, limited research is available concerning the transition to EVs in specific mobility sectors and commercial fleets. One taxi-related EV adoption study from New York in 2008 focusses on buying hybrid electric vehicles (HEVs) and found that $34 \%$ of the taxi drivers preferred purchasing an HEV as their next vehicle, with relevant factors influencing the decision to purchase a HEV being age, experience, and income [3]. However, due to technological progress, recent research interest has shifted from HEVs to FEVs, making this study less applicable to the current context. A recent study by Scoranno, Danielis and Giansoldati on EV taxis in Florence described a similar context to the transition in Amsterdam, whereby municipal policy mandates EV taxi usage and EV adoption being the individual's own decision [4]. The researchers found that taxi drivers were not convinced of EV taxis being suitable vehicles for a taxi service, in large part due to practical issues such as limited driving range and the need to charge during work [4]. Other EV related taxi studies focus on analysis of operating and charging behavior [5]. However, limited research is available on characteristics and preference of taxi drivers within the context of a governmental incentive program that promotes adoption of FEVs.

Two streams of research regarding influential factors concerning EV adoption are discussed [6]: (i) situational factors, being the covenant and the accompanying municipal incentives, and (ii) psychological factors, being an attitude towards vehicle attributes as well as sources consulted in the search for information on EVs.

\subsection{Situational Factors}

Different from other scenarios where covenants or voluntary agreements are used is the fact that, within the Amsterdam based taxi sector, legislation to enforce the EV transition is present and industry 
partners such as taxi organizations (but not individual taxi drivers) are complacent [7]. Examples of this legislation are the different zero-emission zones, which are gradually introduced as the areas in which polluting vehicles (as defined by the municipality) are prohibited, are expanded [8]. Next to these regulatory instruments, stimulating and facilitating incentives are deployed by the municipality as well [8].

Incentives have been widely used to increase the uptake of more expensive niche technologies in sectors dominated by established technology, such as FEVs in an ICEV dominated market. The most traditional stimulating incentive is the financial incentive, often in the form of a tax benefit, used to counter the barrier that is high purchase costs [9]. This is no different for the Amsterdam based taxi sector, with the most straightforward incentive being a subsidy to counter high purchase costs [2]. In the study by Bjerkan, Nørbech and Nordtømme [10], Norwegian Battery Electric Vehicle (BEV) owners emphasize the significance of incentives that reduce purchase costs, as they increase BEV market competitiveness.

Additionally, increasing demand for electric taxis can provide another incentive. This may be achieved through municipal activities to stimulate large users of taxis (e.g., hotels and large businesses) to only select electric taxis [11]. An example of such an initiative is described by Hagman and Langbroek [12] for the city of Stockholm. Increasing demand for electric taxis can furthermore be achieved by creating zero-emission taxi stands, as has also been done in Amsterdam [13].

Other studies [14] show that home location charging and workplace charging are the first and second most influential factors in convincing consumers to purchase a Plug-in Electric Vehicle (PEV), but public (fast) charging infrastructure is likely to be a more fundamental prerequisite for taxi drivers to facilitate a constant driving range suitable for medium- to long-distance passenger transport. This assumption is confirmed by Merksy, Sprei, Samaras and Qian [15], who show that corporate vehicles, such as taxis, rely more on public charging infrastructure by being limited (or restricted) to municipal boundaries. Expanding inner city charging infrastructure can therefore not only facilitate current FEV taxi drivers, but also incentivize potential FEV taxi drivers.

Aside from incentives that focus on cost-related or operational aspects once the vehicle is purchased, individual drivers can also be incentivized in different manners prior to the purchase decision [16]. Due to the effect of word of mouth, Shephard, Bonsall and Harisson [17] suggest that more research into the use of awareness campaigns could be fruitful. This might be particularly relevant in cases where knowledge of FEV technology is limited or distorted [18]. Furthermore, practical experience with an FEV has shown to alter FEV preferences and attitudes [19-21], which may in turn increase the perceived usefulness of other incentives. For instance, car drivers with FEV experience may realize that charging is required less often than initially thought, which may lead to a different perception on the sufficiency of current charging infrastructure.

\subsection{Psychological Factors}

Whereas charging infrastructure is pivotal in facilitating FEVs, the vehicle itself is characterized by attributes that can provoke certain attitudes amongst owners and future buyers. Several EV adoption studies have highlighted the role of attributes extensively $[18,22,23]$, so we will only provide a short review relevant for the theoretical framework used in this research. Based on the literature review, we distinguish four different attributes relevant for $\mathrm{EV}$ adoption and present in sustainable innovations at large: (i) instrumental, (ii) financial, (iii) symbolic and (iv) environmental. Instrumental attributes, or functional attributes [18], concern the most prominent functional key features of a product [23]. Apart from more general factors such as performance and safety [16], for the case of EVs, battery-related aspects such as driving range [24] and uncertainty associated with battery technology [16] are also relevant. Closely related to instrumental attributes, and in studies often included within that attribute, are financial attributes that reflect the factor of costs when purchasing, operating and maintaining an EV. Low maintenance and low operating costs (e.g., charging costs), can for instance be motivators for the purchase of an EV [14]. While some FEVs have a significantly higher purchase price compared 
to conventional vehicles, research on the total cost of ownership (TCO) shows that EVs could be more financially feasible compared to ICEVs for certain user types [25], in large part due to their low operating and maintenance costs.

Symbolic attributes concern the effect of adoption and usage of an EV on the owner's identity and social status $[9,23,26]$ and/or the feelings that an EV provokes [18]. Symbolic aspects are vehicle characteristics such as the style and size of the vehicle [16]. With the term impression management, Graham-Rowe et al. [27] show for instance that potential EV adopters are concerned with the image and identity other EV drivers would form of them when they were to drive an EV. Lastly, regarding environmental attributes, EVs are often cited regarding environmental benefits, such as reduced local carbon emissions, which could provide a motivator to purchase an EV [16,28].

Another relevant socio-psychological factor that influences interest in and intention to adopt FEV concerns the circulation of information and the consultation of information sources to expand a potential adopter's knowledge of EVs [18,29]. Potential adopters of new technology are likely to have insufficient technical and economic understanding of innovative, low carbon technologies, which could lead to misconception about the technology [6]. Exemplary in this respect is the study in which the range of EVs was translated by new drivers to more "attainable measures" [30] (p.65). Additionally, several studies have shown that social influence plays a significant role in EV adoption $[17,31]$ and the assessment of the technology [32] as well. Shepherd, Bonsall and Harrison [17] show that potential EV adopters are more sensitive to the word of mouth effect from ICEV drivers than EV drivers, which can be explained by the dominant presence of ICEV drivers in the early stages of adoption. Thus, negative evaluations from other ICEV drivers result in a decreased willingness to adopt an EV. Similarly, Jansson et al. [31] show that opinion seeking is negatively related to EV adoption, while opinion leadership in combination with personal norms in favor of sustainable vehicles drive EV adoption. In their research on the implementation of EVs within a commercial fleet, Wikström and colleagues show that current EV users can act as ambassadors to promote EV usage, but that co-workers who were less enthusiastic about using an EV could not be persuaded by their ambassador colleagues [30]. In the context of electric taxis, Hagman and Langbroek [12] acknowledge the lack of information on electric taxis in regard to profitability, requirements and limitations.

\subsection{Contribution}

There is growing stream of research on adoption of EVs. Most of the research, however, is focused on adoption of EVs by consumers, rather than professional drivers. Given that taxi drivers are more dependent on the vehicle, will display higher mileage and are influenced by the complex policy context of stimulating, facilitating as well as regulating measures, this leads to questions of how this particular group of professional drivers perceives the policy measures and how their attitude towards EVs can be described.

The aim of this paper then is twofold. First, we want to illustrate the overall interest in purchasing an FEV taxi and the overall intention to purchase an FEV taxi amongst Amsterdam based ICEV taxi drivers. Second, we want to characterize two subgroups within the taxi sector by showing the differences: (i) ICEV drivers with and (ii) ICEV drivers without an interest in purchasing an FEV. We focus on the interest ICEV taxi drivers have in purchasing an FEV and not the intention to purchase an FEV, as the overall intention to purchase an FEV proved to be low amongst ICEV taxi drivers (as will be described in Section 4.1.), making intention not a useful variable to base a distinction upon.

In this study, interest in purchasing an electric taxi indicates a personal interest to purchase an electric vehicle, regardless of whether favorable conditions, such as sufficient finances, and serious intention to purchase an electric taxi, are present. An intention to purchase an electric taxi, on the other hand, means that the individual aims at purchasing an electric taxi vehicle at some point in the near future. This aim does not necessarily signal a specific personal interest or belief in regard to the vehicle: an individual can show a high purchase intention by being environmentally motivated to purchase a 
zero-emission vehicle but could portray an equal high purchase intention as a result of mandatory zero-emission vehicle usage.

\section{Methodology}

\subsection{Sample and Procedure}

A digital survey was sent out to approximately 3000 taxi drivers in September 2017, with a link to the survey and an introductory text included in several online newsletters distributed by several official taxi organizations as well as the municipality of Amsterdam by email. These newsletters were sent to taxi drivers driving Internal Combustion Engine Vehicles (ICEV), Full Electric Vehicles (FEV), Plug-in Hybrid Electric Vehicles (PHEV) and Natural Gas Vehicles (NGV). Out of these 3000 taxi drivers, 307 taxi drivers filled out the survey $(10 \%)$. A total of six responses were excluded from analysis as duplicate responses, resulting in 301 responses used in the analysis. Not all questions were mandatory and therefore some displayed results do not include al 301 responses. In addition, 296 of the 301 respondents specified their current vehicle type, leading to the following distribution: 236 ICEVs $(77.1 \%), 36$ FEVs $(11.8 \%), 12$ PHEVs $(3.9 \%)$ and 12 NGVs (3.9\%). The sample of FEV drivers $(11.8 \%)$ is representative for the share of FEV taxis in the total Amsterdam based taxi fleet, which was expected to be 400 taxis (between 10-12\%) at the time (as of 2019, 27\% of the vehicles of the official Amsterdam based taxi organizations (all of whom signed the covenant) are registered as electric [8]). However, due to (i) the municipal focus on (the adoption of) zero emission vehicles and FEVs, (ii) the low response rate from PHEV and NGV drivers and (iii) our focus on FEV adoption by ICEV drivers, analysis of data reported in the results section will only include all identifiable ICEV drivers $(n=236)$. Since PHEV and NGV taxis were, at the time of the survey, considered as "clean vehicles" by the municipality, these taxi drivers too could experience certain benefits from the municipal incentive program. Hence, their current experiences with incentives and, in the case of PHEVS, their experience with charging and charging infrastructure, might influence their interest in an FEV as well as attitudes towards the covenant and the municipal incentives. Therefore, both NGV and PHEV taxi drivers are not included in the results presented in this paper in order to keep the focus on the group of ICEV taxi drivers.

In regard to the covenant and the incentives, survey questions were preceded by a short explanation clarifying either the covenant or one of the incentives. Three incentives were chosen to be measured in the survey: (i) the charging license, (ii) professional and objective information provision on FEVs and (iii) FEV taxi tryouts. The charging license was an already implemented measure in the municipal incentive program at the time of the survey, the latter two were hypothetical incentives introduced by the researchers based on research interest and stemming from the results of a brief literature review $[6,17,19-21]$.

The charging license consisted of a 30-minute parking license, whereby parking fees were waivered for a maximum of 30 minutes when a parked FEV was charging at a designated non-fast charger within the inner-city district. Professional and objective information provision was described as receiving information from current FEV taxi drivers about driving experiences, as well as information from experts discussing FEV technology, to be set at certain social gatherings. FEV taxi tryouts were described as giving current ICEV taxi drivers the opportunity to lease an FEV taxi for a week (for a small fee), as to experience driving and charging an FEV themselves.

After evaluating the covenant and the incentives, respondents were asked to state their interest and willingness to purchase an FEV. Subsequently, FEV attributes were evaluated and respondents filled out which information sources were consulted when searching for information on FEVs. Lastly, demographic information was collected regarding age, self-reported average number of rides per week and market segments in which the respondent was active. 


\subsection{Measures}

\subsubsection{Acceptability of the Covenant}

Acceptability of the covenant was measured using a single item: "I find the agreement between the municipality of Amsterdam and the Amsterdam based taxi organizations ... " on a 7-point Likert scale, with 1 being very unacceptable and 7 being very acceptable $(\mathrm{M}=2.58, \mathrm{SD}=1.869)$. As the group average shows, acceptability towards the covenant can be considered low.

\subsubsection{Incentives}

For each of the three incentives, respondents were asked whether the incentive made it attractive for the respondent to purchase an FEV (rated on a 7-point Likert scale, 1 making it very unattractive, 7 making it very attractive). Table 1 shows both the mean values and the standard deviations. Additionally, taxi drivers were asked whether the expansion of the fast charging infrastructure in Amsterdam would make them purchase an electric taxi faster.

Table 1. Attractiveness ratings of the incentives.

\begin{tabular}{cl}
\hline Incentive & M (SD) \\
\hline Charging license & $2.76(2.165)$ \\
\hline Professional and objective information provision & $3.03(2.010)$ \\
\hline Full electric vehicle taxi tryouts & $3.48(2.249)$ \\
\hline
\end{tabular}

\subsubsection{Vehicle Attributes}

Attributes were selected based on prior research $[18,26]$ presented in the previous chapter. The set of attributes was altered in two ways, based on the research setting. First, items measuring instrumental attributes were categorized into two distinct categories: instrumental attributes and financial attributes. Second, the existing set of attributes was expanded for this specific group of professional drivers by including an instrumental attribute regarding customer demand and a financial attribute regarding residual value, which we consider important for the research setting.

Items for all four attribute sets were rated on a 6-point Likert scale, thus excluding the option for a neutral stance. The higher the score, the more favorably the attribute was evaluated. All four items sets displayed a high level of internal consistency, with Cronbach's Alpha higher than 0.8 in all four cases. Table 2 displays the items sets, as well as the means and standard deviations for both the individual items reflecting the respective attributes, as the attribute sets themselves. Instrumental attributes ( $\alpha=0.88)$ were measured with five items and reflected fairly negative evaluations $(M=2.31$, $\mathrm{SD}=1.299)$. Financial attributes $(\alpha=0.84)$ were measured with four items reflecting all cost aspects of owning and operation a vehicle. Closely related to the instrumental attributes, financial attributes received similar fairly negative evaluations $(M=2.33, S D=1.321)$. Symbolic attributes $(\alpha=0.83)$ were measured with two items and, surprisingly, received the lowest mean scores $(\mathrm{M}=2.12, \mathrm{SD}=1.305)$ out of the four attribute sets. Environmental attributes $(\alpha=0.88)$ were measured with two items and were the only attributes positively evaluated $(\mathrm{M}=3.72, \mathrm{SD}=1.804)$. 
Table 2. Attribute items and evaluations.

\begin{tabular}{ll}
\hline \multicolumn{1}{c}{ An Electric Car ... } & M (SD) \\
\hline Instrumental Attributes $(\alpha=\mathbf{0 . 8 8})$ & $\mathbf{2 . 3 1 ( \mathbf { 1 . 2 9 } )}$ \\
\hline$\ldots$ is comfortable & $2.71(1.720)$ \\
\hline$\ldots$ is reliable & $2.29(1.546)$ \\
\hline$\ldots$ is safe & $2.49(1.532)$ \\
\hline$\ldots$ can drive long distanced uninterrupted & $1.80(1.591)$ \\
\hline$\ldots$ is in line with customer demand & $2.45(1.666)$ \\
\hline Financial Attributes $(\alpha=\mathbf{0 . 8 4})$ & $\mathbf{2 . 3 3 ( \mathbf { 1 . 3 2 1 } )}$ \\
\hline$\ldots$ is cheap to purchase & $1.82(1.516)$ \\
\hline$\ldots$ is cheap in maintenance & $2.50(1.687)$ \\
\hline$\ldots$ is cheap in usage & $2.91(1.751)$ \\
\hline$\ldots$ gives me a good residual value & $2.17(1.483)$ \\
\hline Symbolic Attributes $(\alpha=0.83)$ & $\mathbf{2 . 1 2 ( 1 . 3 0 5 )}$ \\
\hline$\ldots$ gives me prestige & $2.08(1.370)$ \\
\hline$\ldots$ fits with who I am & $2.16(1.459)$ \\
\hline Environmental Attributes $(\alpha=\mathbf{0 . 8 8 )}$ & $3.72(\mathbf{1 . 8 0 4 )}$ \\
\hline$\ldots$ is environmentally friendly & $3.91(1.883)$ \\
\hline$\ldots$ is not polluting & $3.55(1.934)$ \\
\hline
\end{tabular}

\subsubsection{Information Sources}

Insight into the information sources consulted was surveyed by asking drivers to check the information sources listed which they consulted when acquiring information on FEVs. Options included (a) their taxi organization, (b) conversations with other drivers, (c) a popular taxi newsmagazine, (d) WhatsApp groups with other taxi drivers, (e) Facebook groups with other taxi drivers, (f) car dealerships and (g) car manufacturers' websites. Multiple options could be checked. In most cases where categories ( $\mathrm{d}$-WhatsApp) and (e-Facebook groups) were selected, so was category (b-Conversations with peers). Additionally, respondents were able to add a category themselves as well, but no noteworthy distinguishable categories were mentioned.

\subsubsection{Interest to Purchase an FEV}

The independent variable used within this study, being interest in purchasing an FEV, was measured with a single item: "To what extent are you interested in purchasing an electric taxi in the future?" Respondents answered on a 7-point Likert scale, 1 being completely not interested and 7 being very interested $(\mathrm{M}=2.98, \mathrm{SD}=2.045)$. As the group average shows, slight disinterest in an FEV was shown amongst ICEV drivers. In addition to interest in purchasing an FEV, the self-reported degree of likelihood of purchasing an FEV in the future was measured $(\mathrm{M}=3.30, \mathrm{SD}=2.069)$. Similar to interest, likelihood was measured on a 7 -point scale $(1=$ not likely $\ldots 7=$ very likely $)$.

\subsection{Analysis}

For the analysis, Pearson product-moment correlations were used to assess any correlation between both dependent variables, as well as dependent variables and the independent variable (interest in purchasing an FEV). A Pearson product-moment correlation was used where the variables appeared linearly correlated when scatterplots were inspected. We furthermore consider the Pearson product-moment correlation suitable for Likert scale data. Independent samples $t$-tests, Mann-Whitney U tests and Kruskal-Wallis H-tests were used to assess statistically significant differences between 
subgroups: the ICEV drivers interested in purchasing an FEV versus the ICEV drivers not interested in purchasing an FEV. For some of the analyses, the dependent variable (Likert scale, 7 scores) was recoded into a dichotomous variable, whereby any of the three levels of interest (score 5,6 or 7 ) or any of the three levels of no interest (score 1,2 and 3) were grouped as either interest or no interest in purchasing an FEV. Neutral stances (score 4) were omitted in any analysis that concerns both subgroups.

\section{Results}

\subsection{Interest and Intention in Purchasing an FEV}

Out of the 236 ICEV drivers, 139 (58.9\%) of the ICEV drivers reported a moderate to strong disinterest in purchasing an FEV, $33(14 \%)$ remained neutral in their interest and 64 (27.1\%) showed a moderate to strong interest in purchasing an FEV in the future. Concerning likelihood, $124(52.5 \%)$ ICEV drivers considered it somewhat to very unlikely that they would purchase an FEV in the future, with $45(19.1 \%)$ neutral and $66(28 \%)$ considering it somewhat to very likely.

Using a Pearson's product-moment correlation, a statistically significant, strong positive correlation was found between interest in purchasing an FEV and self-reported likelihood of purchasing an FEV among ICEV drives, $(r(233)=0.73, p<0.001) .110(46.6 \%)$ ICEV drivers displayed a disinterest and unlikelihood in purchasing an FEV versus 47 (19.9\%) ICEV drivers showing interest in purchasing an FEV and considered it likely to purchase an FEV in the future. The remaining ICEV drivers were either interested but did not consider the purchase likely (6 responses, $2.5 \%$ ), were not interested but did consider the purchase likely (11responses, $4.7 \%$ ) or gave a neutral response on either interest or likelihood (61 responses, 25.8\%).

Out of the 90 ICEV drivers (38\%) that reported they were planning to purchase a new taxi vehicle on short notice, only 18 were planning to purchase an FEV, with 12 out of 18 planning to purchase the FEV the following year (2018). None of the ICEV drivers not planning to purchase a new taxi vehicle reported that they were considering their next taxi vehicle to be an FEV. Thus, only $7.6 \%$ of the entire sample of ICEV taxi drivers were planning to purchase an FEV, which can be considered a low overall purchase intention.

\subsection{Demographics}

Eleven taxi drivers did not fill in their age and six outliers were omitted for reporting an age above the retirement age (67). Age was normally distributed for both groups as assessed by the Normal Q-Q Plots. An independent samples $t$-test was used to assess differences in age between both groups. There was homogeneity of variances $(p=0.178)$. ICEV drivers interested in purchasing an FEV $(n=59$, $M=39.59, S D=11.117$ ) were on average slightly, but not statistically significantly older than ICEV drivers not interested in purchasing an FEV $(n=127, M=37.28, S D=12.236), M=2.31,95 \%$ CI [ -1.39 , 6.01], $t(184)=1.233, p=0.219$.

Results from an independent samples $t$-test on the self-reported average number of rides per week include data from 57 taxi drivers interested in purchasing an FEV and 129 taxi drivers not interested in purchasing an FEV. Ten outliers were omitted ( $z$ value $>2.0$ ). Ride frequency was normally distributed for both groups, as stated by the Shapiro-Wilk test $(p>0.05)$ as well as the normal Q-Q plots. Taxi drivers interested in purchasing an FEV $(\mathrm{M}=38.14, \mathrm{SD}=17.263)$ had slightly more rides per week than their counterparts $(M=37.97, \mathrm{SD}=19.552)$. There was homogeneity of variances $(p=0.248)$. There was no statistically significant difference in ride frequency between both groups, $M=0.17,95 \% \mathrm{CI}$ $[-5.75,6.09], t(184)=0.057, p=0.955$.

Concerning segments of the market where the taxi drivers are active, no striking differences can be found between groups. Results are displayed in Table 3. 
Table 3. Market segments.

\begin{tabular}{ccccc}
\hline Market Segment & Interested & $\%$ & Not Interested & $\%$ \\
\hline $\begin{array}{c}\text { Supplementary } \\
\text { airport transport }\end{array}$ & 22 & $18 \%$ & 47 & $16 \%$ \\
\hline Hotel transport & 25 & $21 \%$ & 53 & $18 \%$ \\
\hline Taxi stand & 41 & $34 \%$ & 129 & $44 \%$ \\
\hline Appointment-based & 33 & $27 \%$ & 67 & $23 \%$ \\
\hline
\end{tabular}

The distribution for supplementary airport transport, taxi stands and appointment-based market segments is roughly 1 to 2: for every ICEV taxi driver interested in purchasing an FEV and working in a specific market segment, two other colleagues not interested in purchasing an FEV reported being active in that market segment as well. The only difference is the taxi stand market, where this ratio is 1 to 3: more ICEV drivers not interested in purchasing an FEV have reported being active in this market segment. With taxi stand access being a means by the municipality to enforce zero-emission taxi transport within the inner city by making these stands gradually exclusively available to FEV taxis, taxi drivers active in this market segments might experience more regulative pressure as taxi stands become increasingly accessible exclusively to FEV taxis. However, based on the data presented in Table 3, no noteworthy differences can be found between both groups, other than the fact that FEV-interested taxi drivers are less represented in the taxi stand market segment.

\subsection{Attitude towards the Covenant}

Acceptability of the covenant was low among the total group of ICEV drivers ( $\mathrm{M}=2.58, \mathrm{SD}=1.869)$. A moderate positive significant correlation was found between overall interest in purchasing an FEV and acceptability of the covenant, $r(234)=0.59, p<0.001$. Using a Mann-Whitney U test, whereby distributions of acceptability towards the covenant were similar, median engagement scores were significantly higher in ICEV drivers interested in purchasing an FEV $(M d n=4)$ than ICEV drivers not interested in purchasing an FEV $(M d n=1), U=1.5735, z=-7.2962, p<0.001$.

\subsection{Incentives}

As the rated attractiveness scores for all three incentives were not normally distributed, three independent Mann-Whitney $U$ tests were conducted to determine differences between groups. Due to the nature of ordinal data, outliers were kept. For all three incentives, distributions of both groups were not similar. Results are shown in Table 4.

Table 4. Results of Mann-Whitney $U$ tests on the rated attractiveness of the municipal incentives.

\begin{tabular}{lccccc}
\hline $\begin{array}{c}\text { Municipal } \\
\text { Incentive }\end{array}$ & $\begin{array}{c}\text { Mean Rank } \\
\text { Interested Group }\end{array}$ & $\begin{array}{c}\text { Mean Rank Not } \\
\text { Interested Group }\end{array}$ & $\mathbf{U}$ & $\mathbf{z}$ & $\boldsymbol{p}$ \\
\hline Parking license & 143.77 & 82.34 & 1.7155 & -7.482 & $<0.001$ \\
\hline $\begin{array}{l}\text { Full electric } \\
\text { vehicle tryout }\end{array}$ & 139.50 & 84.73 & 2.048 & -6.348 & $<0.001$ \\
\hline $\begin{array}{l}\text { Information } \\
\text { provision }\end{array}$ & 144.37 & 82.07 & 1.6775 & -7.302 & $<0.001$ \\
\hline
\end{tabular}

ICEV taxi drivers interested in purchasing an FEV rated all three incentives as statistically significantly more attractive than their colleagues. This could mean that targeting FEV-interested drivers with these incentives might further motivate these taxi drivers to switch to an FEV taxi.

Concerning fast charging infrastructure, $80.9 \%$ of ICEV taxi drivers interested in purchasing an FEV stated that they would purchase an electric vehicle faster if more fast chargers were installed, 
compared to $24.3 \%$ of the ICEV taxi drivers not interested in purchasing an FEV giving the same answer. The data thus suggest that availability of charging infrastructure may provide a powerful lever for stimulating taxi drivers to switch.

\subsection{Vehicle Attributes}

Bivariate correlations coefficients, shown in Table 5, revealed a statistically significant and strong positive correlation between financial and instrumental attributes $(r=0.840)$. This was expected, as instrumental (e.g. performance) and financial attributes (e.g. cost-related aspects) are closely related, and financial attributes are often incorporated as instrumental attributes in other EV adoption studies. Other statistically significant moderate positive correlations $(r>0.6)$ were found between instrumental and symbolic attributes (e.g., style and brand) $(r=0.654)$ and symbolic attributes and interest in purchasing an FEV $(r=0.622)$.

Table 5. Bivariate correlations coefficients between the evaluations of the four different attributes and interest in purchasing an FEV.

\begin{tabular}{lcccc}
\hline \multicolumn{1}{c}{ Attributes } & Symbolic & Financial & Environmental & FEV Interest \\
\hline Instrumental & $0.654^{* *}$ & $0.840^{* *}$ & $0.380^{* *}$ & $0.478^{* *}$ \\
\hline Symbolic & & $0.593^{* *}$ & $0.386^{* *}$ & $0.622^{* *}$ \\
\hline Financial & & $0.366^{* *}$ & $0.522^{* *}$ \\
\hline Environmental & & & $0.364^{* *}$ \\
\hline
\end{tabular}

Of all the individual items (as displayed in Table 2), six items were positively evaluated (group mean $>3.5$ ) by FEV-interested taxi drivers when analyzing mean values: EVs were considered comfortable $(M=3.53)$, cheap in usage $(M=3.97)$, environmentally friendly $(M=4.88)$, not polluting $(M=4.72)$ cheap in maintenance $(M=3.76)$ and in line with customer demand $(M=3.56)$. Taxi drivers not interested in purchasing an FEV only positively evaluated the environmentally friendliness of the vehicle $(M=3.53)$. In two items, the differences in mean scores between both groups is the smallest: both groups agree that an FEV is not cheap to purchase (group interested, $M=2.38$ and group not interested, $M=1.55$ ) and cannot drive long distances uninterrupted (group interested, $M=2.35$ and group not interested, $M=1.58$ ). On topics of pricing and range, the groups thus coincide, but, on attributes regarding environmental benefits, maintenance and customer demand, differences in perceptions between the two groups exist.

Four independent Mann-Whitney $U$ tests were conducted to analyze group differences. Since it concerns ordinal data, reported outliers were kept. For all four attribute sets, data were not normally distributed for either one or both groups, and, in all four cases, distributions for both groups were not similarly shaped. Data are displayed in Table 6.

Table 6. Results of Mann-Whitney U tests on evaluations of EV attributes.

\begin{tabular}{lccccc}
\hline Attributes & $\begin{array}{c}\text { Mean Rank } \\
\text { Interested Group }\end{array}$ & $\begin{array}{c}\text { Mean Rank Not } \\
\text { Interested Group }\end{array}$ & U & z & $p$ \\
\hline Instrumental & 134.43 & 79.26 & 1.6845 & -6.424 & $<0.001$ \\
\hline Financial & 140.34 & 77.85 & 1.4435 & -7.256 & $<0.001$ \\
\hline Symbolic & 142.22 & 77.30 & 1.426 & -7.828 & $<0.001$ \\
\hline Environmental & 132.81 & 84.44 & 2.220 & -5.595 & $<0.001$ \\
\hline
\end{tabular}

Results show that, concerning all four attributes, scores were statistically significantly higher for taxi drivers interested in purchasing an FEV than their not interested colleagues. Instrumental, financial, 
symbolic and environmental attributes were thus all evaluated better by taxi drivers interested in purchasing an FEV than their colleagues.

\subsection{Information Sources Consulted}

Consulting colleagues or objective information sources for EV information does not have to be a dichotomy, as taxi drivers can consult both or neither sources as well. However, based on mean group values, interest in purchasing an FEV was highest among taxi drivers only consulting objective information sources ( $n=65, M=3.38, S D=1.990)$, followed by taxi drivers consulting both objective and social information sources $(n=73, M=3.19, S D=2.139)$, consulting neither social nor objective information sources $(n=29, M=2.69, S D=1.892)$ and consulting only social information sources $(n=69, M=2.49, S D=1.982)$.

A Shapiro-Wilk test showed 'interest in purchasing an FEV' score was not normally distributed for all four groups $(p<0.001)$, thus a Kruskal-Walls $\mathrm{H}$ test was run to determine whether significant differences in interest in an FEV between the four groups existed. Distribution of 'interest in purchasing an FEV' scores was similar for all four groups (as shown in boxplots), with median scores statistically significantly different between groups, $X^{2}(3)=9.072, p=0.028$. Using pairwise comparisons, post hoc analysis shows statistically significant differences in 'interest in purchasing an FEV' scores between the group consulting only social information sources $(M d n=1)$ and the group consulting only objective information sources $(M d n=4)(p=0.029)$. No statistically significant differences were found in any other group combination.

\section{Discussion}

Striking in the results is that, despite the covenant and the clear objective of $100 \%$ electric vehicles by 2025, the majority of ICEV taxi drivers have no interest in purchasing an FEV and negatively evaluate both the supporting measures as well as most of the EV attributes. Given that the research was carried out in 2017, the actual portfolio of EVs on the market and their performance are likely to have an influence on the results. Available models and performance have increased at a rapid pace, which could lead to significant differences in interest over the years, the reason that follow-up, longitudinal work should be carried out to establish any changes in perspectives by ICEV taxi drivers.

\subsection{Policy Implications}

We highlight two implications of the results for policy makers. First, the implementation of objective information provision could be particularly useful in targeting taxi drivers who do not consult any objective information sources at all, but instead rely on colleagues for information, which could create misperceptions or skewed information depending on the attitude and perceptions of the colleagues consulted. Objective information could furthermore debunk possible myths regarding instrumental and financial attributes, especially regarding vehicle range and purchase price as the technology develops. It is therefore recommended that policy makers with an interest in stimulating taxi drivers (or other close-knit mobility sectors such as city logistics) set up a structured information campaign to reach the relevant target group in order to provide objective information as well as answer urgent questions that are likely to emerge related to innovative technology such as electric taxis.

Second, expanding fast charging infrastructure could provide a powerful incentive to further incentivize this group of ICEV drivers. Results do hint that expansion of the fast charging infrastructure might be more beneficial than the parking license incentive. Earlier research has suggested that charging infrastructure is a relevant pre-condition for regular car owners to switch to electric [33]; this research expands this thesis to the enabling character fast charging may have for heavy users such as taxi drivers. Further work should be done to substantiate this finding. 


\subsection{Limitations of the Study and Further Research}

Several limitations exist within the current study. First, more incentives could play a role within the transition to FEV taxi transport, such as the implementation of FEV exclusive taxi stands like Schiphol Airport. Additionally, we did not include the purchase subsidy ( $€ 5.000,-)$ as provided by the municipality per FEV, as all taxi drivers that bought an FEV taxi in the last year applied for this subsidy. Second, limitations to the study include that we know how certain attributes of an FEV are evaluated but not why these attributes received a certain evaluation. Research into more psychological factors that underlie particular ratings would be beneficial in unraveling these ratings. Third, insights into opinion leading and opinion following [31] might reveal which taxi drivers are more likely to consult objective information sources and which taxi drivers consult peers.

Further research could also include a comparison between EV adopters from different professional mobility sectors and consumers. Such a comparison could highlight differences between EV adopter segments in relation to vehicle attributes, demographics, as well as attitude towards and the impact of policy and accompanying incentives and measures.

The municipality does not have to be the only actor in the wider field of the EV transition to provide external incentives. Vehicle lease deals tailored to the needs of taxi drivers could counter several financial barriers, such as purchase costs. Equal rules for both official taxi organizations as well as other mobility actors, such as Uber, would provide a level playing field. Further research should focus on the role and influence of external actors on the transition to a full electric taxi fleet. Simultaneously, it should be noted that the attractiveness of the incentives can differ over time: a parking license incentive might prove attractive to a potential adopter if few colleagues apply for this license and charging stations are widely available, whereas unavailable and crowded charging stations can diminish the perceived attractiveness of the incentive. We therefore want to emphasize that measuring the perceived attractiveness or acceptability of an incentive should be done regarding the context and the phase of the transition.

\section{Conclusions}

This paper provides an example of innovative policy practices put in place to stimulate a commercial mobility sector (taxis in Amsterdam) to become electric. The incentives and regulations put in place have allowed to gain more insight into perspectives from taxi owners, particularly the group that is currently still driving ICEV but by 2025 should drive electric.

Results show that $27.1 \%$ of the sample of ICEV taxi drivers were interested in purchasing an electric taxi. However, based on mean values, the overall intention to purchase an FEV taxi across the entire sample was low at the time of the survey distribution, with only 18 drivers $(7.6 \%)$ of the entire sample planning to purchase a new FEV taxi.

Based on the analysis of differences between the two groups, several conclusions can be made. No statistically significant differences in age or ride frequency were found between the two subgroups. While taxi drivers interested in the purchase of an FEV were somewhat underrepresented in the taxi stand market segment, we do not consider this a noteworthy difference.

Concerning situational factors, taxi drivers interested in purchasing an FEV showed a higher acceptance of the covenant than their colleagues not interested in purchasing an FEV and also rated the three incentives included in the study as more attractive. Additionally, $80.9 \%$ of ICEV taxi drivers interested in purchasing an FEV stated that they would purchase an electric vehicle faster if more fast chargers were installed, compared to $24.3 \%$ of the ICEV taxi drivers not interested in purchasing an FEV giving the same answer.

Concerning psychological factors, FEV-interested ICEV drivers evaluated all four attributes of an FEV higher than their colleagues. A comparison in mean values between both groups shows that, unlike taxi drivers not interested in purchasing an FEV, their counterparts rated the FEV as comfortable, cheap in usage, not polluting, cheap in maintenance and in line with customer demand. Both groups agree that an FEV is not cheap to purchase and cannot drive long distances uninterrupted. Lastly, 
taxi drivers consulting only objective information sources regarding FEVs showed more interest in purchasing an FEV than their colleagues consulting only other colleagues on the same topic.

Author Contributions: Conceptualization, M.T.; methodology, M.T.; formal analysis, M.T.; investigation, M.T.; data curation, M.T.; writing—original draft preparation, M.T. and R.v.d.H.; writing — review and editing, M.T. and R.v.d.H.; supervision, R.v.d.H.; project administration, M.T.; funding acquisition, R.v.d.H. All authors have read and agreed to the published version of the manuscript.

Funding: This research is part of the research program U-SMILE (Urban Smart Measures and Incentives for quality of Life Enhancement) with project number 438-15-176, which is financed by the Netherlands Organisation for Scientific Research (NWO).

Acknowledgments: We would like to thank Nadja Zeiske from the Rijksuniversiteit Groningen (RuG) for collaborating with us on this research and for providing feedback on an earlier version of this paper.

Conflicts of Interest: The authors declare no conflict of interest.

\section{References}

1. Netherlands Enterprise Agency. Statistics Electric Vehicles in the Netherlands. 2019, pp. 1-7. Available online: https://www.rvo.nl/sites/default/files/2019/11/Statistics\%20Electric\%20Vehicles\%20and\%20Charging\% 20in\%20The\%20Netherlands\%20up\%20to\%20and\%20including\%20October\%202019.pdf (accessed on 15 November 2019).

2. Gemeente Amsterdam. Convenant Schone Taxi's voor Amsterdam. 2016, pp. 1-8. Available online: https://assets.amsterdam.nl/publish/pages/865246/convenant_schone_taxis_amsterdam.pdf (accessed on 14 October 2019).

3. Goa, H.O.; Kitirattragarn, V. Taxi owners' buying preferences of hybrid-elecitrc vehicles and their implications for emissions in New York City. Transp. Res. Part A 2008, 42, 1064-1073.

4. Scoranno, M.; Danielis, R.; Giansoldati, M. Mandating the use of the electric taxis: The case of Florence. Transp. Res. Part A 2020, 132, 402-414. [CrossRef]

5. Kim, J.; Lee, S.; Kim, K.S. A study on the activation plan of electric taxi in Seoul. J. Clean. Prod. 2017, 146, 1-11. [CrossRef]

6. Lane, B.; Potter, S. The adoption of cleaner vehicles in the UK: Exploring the consumer attitude-action gap. J. Clean. Prod. 2007, 15, 1085-1092. [CrossRef]

7. Lyon, T.P.; Maxwell, J.W. Self-regulation, taxation and public voluntary environmental agreements. J. Public Econ. 2003, 87, 1453-1486. [CrossRef]

8. Gemeente Amsterdam. Actieplan Schone Lucht. 2019, pp. 1-50. Available online: https://www.ggd. amsterdam.nl/publish/pages/910216/actieplan_schone_lucht_2019.pdf (accessed on 14 October 2019).

9. Rezvani, Z.; Jansson, J.; Bodin, J. Advances in consumer electric vehicle adoption research: A Review and research agenda. Transp. Res. Part D 2015, 34, 122-136. [CrossRef]

10. Bjerkan, K.Y.; Nørbech, T.E.; Nordtømme, M.E. Incentives for promotiring Battery Electric Vehicles (BEV) adoption in Norway. Transp. Res. Part D 2016, 43, 169-180. [CrossRef]

11. Edler, J.; Yeow, J. Connecting demand and supply: The role of intermediation in public procurement of innovation. Res. Policy 2016, 45, 414-426. [CrossRef]

12. Hagman, J.; Langbroek, J.H.M. Conditions for electric vehicle taxi: A case study in the Greater Stockholm region. Int. J. Sustain. Transp. 2018, 13, 450-459. [CrossRef]

13. Van den Hoed, R.; Maase, S.; Helmus, J.; Wolbertus, R.; el Bouhassani, Y.; Dam, J.; Tamis, M.; Jablonska, B. E-Mobility: Getting Smart with Data; Amsterdam University of Applied Science: Amsterdam, The Netherlands, 2019; pp. 139-151.

14. Hardman, S.; Jenn, A.; Tal, G.; Axsen, J.; Beard, G.; Daina, N.; Figenbaum, E.; Jakobsson, N.; Jochem, P.; Kinnear, N.; et al. A review of consumer preferences of and interactions with electric vehicle charging infrastructure. Transp. Res. Part D 2018, 62, 508-523. [CrossRef]

15. Mersky, A.C.; Sprei, F.; Samaras, C.; Qian, Z. Effectiveness of incentives on electric vehicle adoption in Norway. Transp. Res. Part D 2016, 46, 56-68. [CrossRef]

16. Egbue, O.; Long, S. Barriers to widespread adoption of electric vehicles: An analysis of consumer attitudes and perceptions. Energy Policy 2012, 48, 717-729. [CrossRef] 
17. Shepherd, S.; Bonsall, P.; Harrison, G. Factors affecting future demand for electric vehicles: A model based study. Transp. Policy 2012, 20, 62-74. [CrossRef]

18. Axsen, J.; Langman, B.; Goldberg, S. Confusion of innovations: Mainstream consumer perceptions and misperceptions of electric-drive vehicles and charging programs in Canada. Energy Res. Soc. Sci. 2017, 27, 163-173. [CrossRef]

19. Jensen, A.F.; Cherchi, E.; Mabit, S.L. On the stability of preferences and attitudes before and after experiencing an electric vehicle. Transp. Res. Part D 2013, 25, 24-32. [CrossRef]

20. Schmalfuß, F.; Mühl, K.; Krems, J.F. Direct experience with battery electric vehicles (BEVs) matters when evaluating vehicle attributes, attitude and purchase intention. Transp. Res. Part F 2017, 46, 47-69. [CrossRef]

21. Bühler, F.; Cocron, P.; Neumann, I.; Franke, T.; Krems, J.F. Is EV experience related to EV acceptance? Results from a German field study. Transp. Res. Part F 2014, 25, 34-49. [CrossRef]

22. Schuitema, G.; Anable, J.; Skippon, S.; Kinnear, N. The role of instrumental, hedonic and symbolic attributes in the intention to adopt electric vehicles. Transp. Res. Part A 2013, 48, 39-49. [CrossRef]

23. Noppers, E.H.; Keizer, K.; Bockarjova, M.; Steg, L. The adoption of sustainable innovations: The role of instrumental, environmental, and symbolic attributes for earlier and later adopters. J. Environ. Psychol. 2015, 44, 74-84. [CrossRef]

24. Coffman, M.; Bernstein, P.; Wee, S. Electric vehicles revisited: A review of factors that affect adoption. Transp. Rev. 2017, 37, 79-93. [CrossRef]

25. Bubeck, S.; Tomascheck, J.; Fahl, U. Perspectives of electric mobility: Total cost of ownership of electric vehicles in Germany. Transp. Policy 2016, 50, 63-77. [CrossRef]

26. Noppers, E.H.; Keizer, K.; Bolderdijk, J.W.; Steg, L. The adoption of sustainable innovations: Driven by symbolic and environmental moties. Glob. Environ. Chang. 2014, 25, 52-62. [CrossRef]

27. Graham-Rowe, E.; Gardner, B.; Abraham, C.; Skippon, S.; Dittmar, H.; Hutchins, R.; Stannard, J. Mainstream consumers driving plug-in battery electric and plug-in hybrid electric cars: A qualitative analysis of responses and evaluations. Transp. Res. Part A 2012, 46, 140-153. [CrossRef]

28. Biresselioglu, M.E.; Kaplan, M.D.; Yilmaz, B.K. Electric mobility in Europe: A comprehensive review of motivators and barriers in decision making processes. Transp. Res. Part A 2018, 109, 1-13. [CrossRef]

29. van Rijnsoever, F.; Farla, J.; Dijst, J.M. Consumer car preferences and information search channels. Transp. Res. Part D 2009, 14, 334-342. [CrossRef]

30. Wikström, M.; Hansson, L.; Alvfors, P. Investigating barriers for plug-in electric vehicle deployment in fleets. Transp. Res. Part D 2016, 49, 59-67. [CrossRef]

31. Jansson, J.; Nordlund, A.; Westin, K. Examining drivers of sustainable consumption: The influence of norms and opinion leadership on electric vehicle adoption in Sweden. J. Clean. Prod. 2017, 154, 176-187. [CrossRef]

32. Axsen, J.; Kurani, K.S. Interpersonal influence in the early plug-in hybrid market: Observing social interactions with an exploratory multi-method approach. Transp. Res. Part D 2011, 16, 150-159. [CrossRef]

33. Liao, F.; Molin, E.; van Wee, B. Consumer preferences for electric vehicles: A literature review. Transp. Rev. 2015, 37, 1-24. [CrossRef]

(C) 2020 by the authors. Licensee MDPI, Basel, Switzerland. This article is an open access article distributed under the terms and conditions of the Creative Commons Attribution (CC BY) license (http://creativecommons.org/licenses/by/4.0/). 